\title{
Magnesium Levels in Drinking Water and Coronary Heart Disease Mortality Risk: A Meta-Analysis
}

\author{
Lei Jiang ${ }^{1,+}{ }^{+}$Pengcheng He ${ }^{1,+}$, Jiyan Chen ${ }^{1}$, Yong Liu ${ }^{1}$, Dehui Liu ${ }^{1}$, Genggeng Qin ${ }^{2}$ and \\ Ning Tan ${ }^{1, *}$ \\ Received: 19 September 2015; Accepted: 30 November 2015; Published: 2 January 2016 \\ 1 Department of Cardiology, Guangdong Cardiovascular Institute, Guangdong General Hospital, \\ Guangdong Academy of Medical Sciences, Guangzhou 510000, China; leijiang223@sina.com (L.J.); \\ pengchenghe223@163.com (P.H.); jiyanchen888@yeah.net (J.C.); yongliu223@sina.com (Y.L.); \\ dehuiliu123@sina.com (D.L.) \\ 2 Department of Radiology, Nanfang Hospital, Southern Medical University, Guangzhou 510000, China; \\ genggengqin123@163.com \\ * Correspondence: ningtan888@yeah.net; Tel./Fax: +86-205-026-8475 \\ + These authors contributed equally to this work
}

\begin{abstract}
Epidemiological studies have demonstrated inconsistent associations between drinking water magnesium levels and risk of mortality from coronary heart disease (CHD); thus, a meta-analysis was performed to assess the association between them. Relevant studies were searched by the databases of Cochrane, EMBASE, PubMed and Web of Knowledge. Pooled relative risks (RR) with their $95 \% \mathrm{CI}$ were calculated to assess this association using a random-effects model. Finally, nine articles with 10 studies involving 77,821 CHD cases were used in this study. Our results revealed an inverse association between drinking water magnesium level and CHD mortality $(R R=0.89$, $95 \% \mathrm{CI}=0.79-0.99, I^{2}=70.6$ ). Nine of the 10 studies came from Europe, and the association was significant between drinking water magnesium level and the risk of CHD mortality ( $R R=0.83,95 \%$ $\mathrm{CI}=0.69-0.98)$. In conclusion, drinking water magnesium level was significantly inversely associated with CHD mortality.
\end{abstract}

Keywords: magnesium; coronary heart disease; mortality; meta-analysis

\section{Introduction}

Coronary heart disease (CHD) killed almost seven million people worldwide in 2010, accounting for the largest fraction of death causes and years of life lost [1] and may be the main cause of disease burden worldwide by 2020 [2], thus, primary prevention of CHD is of significant concern. In 1979, an association between water hardness (hardness of drinking water is largely determined by its calcium and magnesium content) and the risk of CHD mortality was reported [3].

It has previously been reported that drinking magnesium-rich water may be beneficial [4]. A prior study also suggested that the daily intake of magnesium is lower in developed countries [5]. Magnesium deficiency has been shown to predispose to cardiac arrhythmias through a variety of mechanisms [6]. Postmortem studies of people who suddenly died from CHD have found significantly lower levels of magnesium in uninfarcted heart muscle [7]. The evidence suggests that levels of magnesium in drinking water may affect mortality, if not morbidity, due to CHD [4]. Up to now, many studies have been conducted to investigate the association between drinking water magnesium levels and CHD mortality risk, with inconsistent results. To our knowledge, there has been no comprehensive meta-analysis to assess this association; therefore, we conducted this study to see if any correlation exists between drinking water magnesium levels and CHD mortality. 


\section{Methods}

\subsection{Literature Search Strategies}

The relevant articles were identified by searching the databases of Cochrane, EMBASE, PubMed and Web of Knowledge written in English. The following search strategy was carried out: (magnesium OR Mg OR drinking water) AND (coronary heart disease (CHD) OR myocardial infarction (MI) OR ischemic heart disease (IHD)) AND (mortality). The references list was also reviewed to include all the related articles.

\subsection{Eligibility Criteria}

The current analysis included all the observational studies which reported drinking water magnesium levels and CHD mortality risk. The outcome measure was the incidence of the mortality of CHD or IHD or MI. The exposure of interest was drinking water magnesium levels. All included studies provided the relative risks (RR) or odds ratio (OR) and their $95 \%$ confidence intervals (CI), or provided enough data to calculate them. If the articles werefrom the same study or same populations, we then included only the most recent study; reviews or letters to the editor were excluded.

\subsection{Data Extraction}

All papers that were chosen based on the detailed search strategy were read by two of the authors (Lei Jiang and Pengcheng He). The following information was taken from each study: the publication years, study type, geographic locations, sex, number of participants, the results of CHD mortality outcome and the adjustment factors. The RR estimates and 95\% CI for drinking water magnesium levels and CHD mortality risk were also extracted. We extracted the multivariable RR and its $95 \%$ CI if possible. Otherwise, we abstracted the crude RR estimates.

\subsection{Statistical Methods}

The inverse variance-weighted mean of the logarithm of RR and their 95\% CI was calculated to evaluate the association between drinking water magnesium levels and CHD mortality. A random-effects model was used to combine study-specific RR (95\% CI) [8]. Heterogeneity was assessed by Cochran $Q$ and $I^{2}$ statistics [9]. Meta-regression analysis and subgroup analysis (study type, geographic locations, CHD outcomes and sex) were conducted to explore the potentially important covariate on the high heterogeneity if possible [10]. The small study effect was tested by Egger's test [11]. Sensitivity analysis [12] was performed for removal of an individual study if the pooled RR lay out of the $95 \%$ CI. All the analyses were performed by STATA version 10.0. A 2-tailed $p$ value of $<0.05$ represented significance.

\section{Results}

\subsection{Study Characteristics}

Five hundred eighty-seven articles from PubMed, 432 articles from Cochrane database, 561 articles from EMBASE and 632 articles from the Web of Knowledge were selected by our search strategy. After reviewing the title/abstract, 72 articles were reviewed in full, 63 of which were subsequently excluded for various reasons. One paper reported the males and females respectively for the association between drinking water magnesium levels and the risk of CHD mortality [13]. Therefore, we put them as two separate studies. Finally, nine articles [3,13-20] involving 77,821 cases were included in this study. These articles included three cohort studies and seven retrospective studies. Figure 1 showed the flow diagram for our literature search. The characteristics of included studies are listed in Table 1. Four studies came from Sweden, two from Netherlands, two from Finland, one from England and one from China. 
Table 1. Characteristics of studies on the levels of magnesium in drinking water and CHD mortality risk.

\begin{tabular}{|c|c|c|c|c|c|c|c|c|}
\hline Study Year & Country & $\begin{array}{l}\text { Study } \\
\text { Design }\end{array}$ & $\begin{array}{l}\text { Participants } \\
\text { (Cases) }\end{array}$ & $\begin{array}{l}\text { Age } \\
\text { (Years) }\end{array}$ & $\begin{array}{l}\text { CHD } \\
\text { Outcome } \\
\end{array}$ & Category $(\mathrm{mg} / \mathrm{L})$ & $\begin{array}{l}\text { RR }(95 \% \text { CI) for Highest } \\
\text { Versus Lowest Category }\end{array}$ & Adjustment for Covariates \\
\hline Leurs et al. 2010 & Netherlands & $\begin{array}{l}\text { Prospective } \\
\text { study }\end{array}$ & $33,258(1642)$ & $55-69$ & IHD & $\begin{array}{c}\text { Male } \\
1.7-3.8 \\
4.2-6.0 \\
6.0-8.0 \\
8.0-8.2 \\
8.5-26.2 \\
\text { Female } \\
1.7-3.8 \\
4.2-6.0 \\
6.0-8.0 \\
8.0-8.2 \\
8.5-26.2\end{array}$ & $\begin{array}{c}\text { Male } \\
1 \\
1.04(0.76-1.42) \\
1.21(0.87-1.71) \\
0.95(0.67-1.33) \\
1.23(0.82-1.86) \\
\text { Female } \\
1 \\
1.08(0.73-1.58) \\
0.75(0.49-1.18) \\
0.97(0.62-1.53) \\
0.89(0.50-1.59)\end{array}$ & $\begin{array}{l}\text { Adjusted for Age, current smoking, number of cigarettes } \\
\text { smoked, years of active smoking, diabetes, hypertension, } \\
\text { BMI, dietary calcium, dietary magnesium, saturated fat, } \\
\text { monounsaturated fat, polyunsaturated fat, fruit and } \\
\text { vegetable consumption, alcohol consumption, total energy } \\
\text { intake (kilocalories), physical activity, educational level, } \\
\text { volume of water consumption, magnesium or calcium } \\
\text { concentration in tap water (depending on the exposure } \\
\text { variable), use of diuretics, and use of multivitamins with } \\
\text { minerals or calcium supplementation }\end{array}$ \\
\hline Luoma et al. 1983 & Finland & $\begin{array}{l}\text { Case-control } \\
\text { study }\end{array}$ & $100(50)$ & $30-64$ & MI & Highest $v$ s. lowest & $1.63(0.62-4.52)$ & Adjusted for age and municipality with the cases. \\
\hline Maheswaran et al. 1999 & England & $\begin{array}{l}\text { Case-control } \\
\text { study }\end{array}$ & $2,496,659(64,226)$ & $\geqslant 45$ & IHD & Highest $v$ s. lowest & $1.01(0.96-1.05)$ & $\begin{array}{l}\text { Adjusted for Age, sex, Carstairs deprivation quintile and } \\
\text { geographical gradients. }\end{array}$ \\
\hline Punsar et al. 1979 & Finland & $\begin{array}{l}\text { Prospective } \\
\text { study }\end{array}$ & $1711(198)$ & $40-59$ & CHD & Highest $v s$. lowest & $0.64(0.44-0.91)$ & $\mathrm{Na}$ \\
\hline Rosenlund et al. 2005 & Sweden & $\begin{array}{l}\text { Case-control } \\
\text { study }\end{array}$ & 458 (116) & $45-70$ & IHD & $\begin{array}{c}0.20-0.9 \\
0.9-1.9 \\
1.9-3.5 \\
3.5-19.2\end{array}$ & $\begin{array}{c}1 \\
1.07(0.73-1.55) \\
0.86(0.59-1.26) \\
0.97(0.66-1.41)\end{array}$ & $\begin{array}{l}\text { Adjusted for Age, sex, catchment area, smoking, } \\
\text { hypertension, socioeconomy, job strain, diabetes mellitus, } \\
\text { body mass index, and physical inactivity. }\end{array}$ \\
\hline Rubenowitz et al. 1996 & Sweden & $\begin{array}{l}\text { Case-control } \\
\text { study }\end{array}$ & $1843(854)$ & $50-69$ & IHD & $\begin{array}{c}\leqslant 3.5 \\
3.6-6.8 \\
6.9-9.7 \\
\geqslant 9.8\end{array}$ & $\begin{array}{c}1 \\
0.88(0.66-1.16) \\
0.70(0.53-0.93) \\
0.65(0.50-0.84) \\
\end{array}$ & Adjusted for Age and magnesium and calcium, respectively. \\
\hline Rubenowitz et al. 1999 & Sweden & $\begin{array}{l}\text { Case-control } \\
\text { study }\end{array}$ & $1746(378)$ & $50-69$ & IHD & $\begin{array}{c}\leqslant 3.4 \\
3.5-6.7 \\
6.8-9.8 \\
\geqslant 9.9\end{array}$ & $\begin{array}{c}1 \\
1.08(0.78-1.49) \\
0.93(0.64-1.34) \\
0.70(0.50-0.99)\end{array}$ & Adjusted for Age and magnesium and calcium, respectively. \\
\hline Rubenowitz et al. 2000 & Sweden & $\begin{array}{l}\text { Case-control } \\
\text { study }\end{array}$ & $521(263)$ & $50-74$ & IHD & Highest $v s$. lowest & $0.64(0.42-0.97)$ & Adjusted for Age and magnesium and calcium, respectively. \\
\hline Yang et al. 2006 & China & $\begin{array}{l}\text { Case-control } \\
\text { study }\end{array}$ & $20,188(10,094)$ & $50-69$ & IHD & $\begin{array}{c}\leqslant 7.7 \\
7.8-13.5 \\
14.1-41.3\end{array}$ & $\begin{array}{c}1 \\
1.00(0.93-1.08) \\
1.09(0.99-1.19)\end{array}$ & $\begin{array}{l}\text { Adjusted for Age, sex, urbanization level of residence, and } \\
\text { magnesium and calcium levels in drinking water respectively. }\end{array}$ \\
\hline
\end{tabular}

Abbreviations: CHD, coronary heart disease; IHD, ischemic heart disease; MI, myocardial infarction; BMI, body mass index; $\mathrm{CI}$, confidence interval; RR, relative risk; Na, not available. 


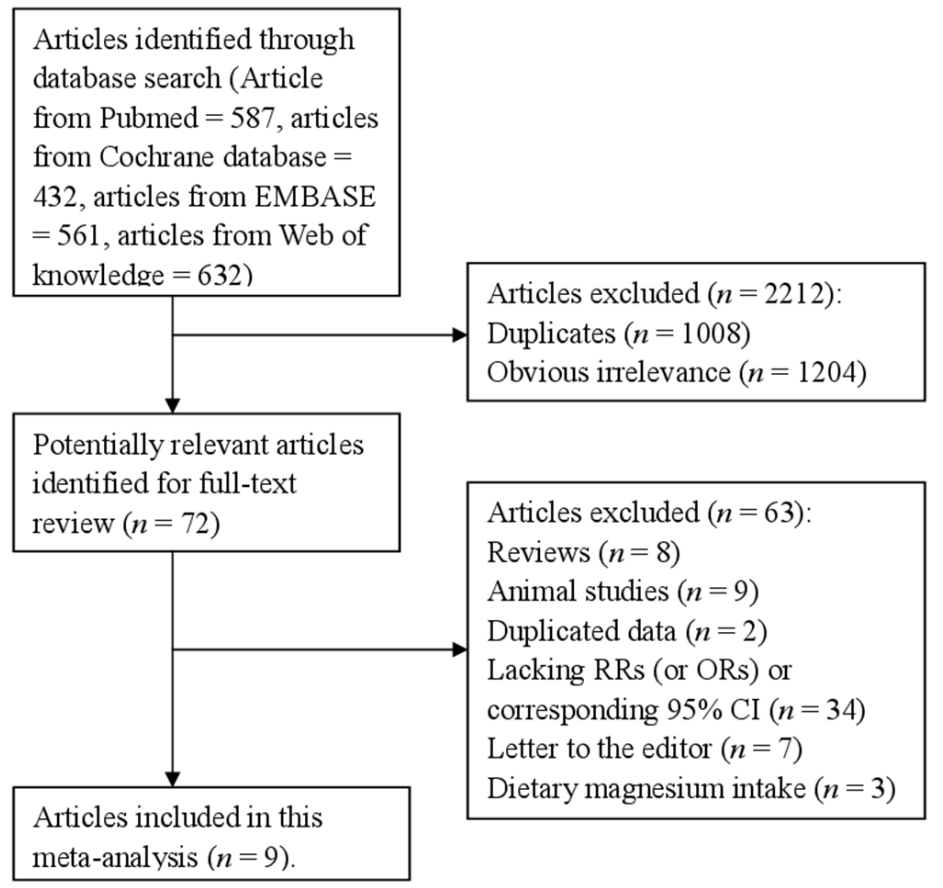

Figure 1. The flow diagram of screened, excluded, and analyzed publications.

\subsection{High versus Low Analyses}

Four studies reported that higher drinking water magnesium levels may reduce the CHD mortality risk, while four studies reported an increase but nonsignificant association. When we pooled the overall results, the association was significant between drinking water magnesium levels and CHD mortality risk $\left(\mathrm{RR}=0.89 \%, 95 \% \mathrm{CI}=0.79-0.99, \mathrm{I}^{2}=70.6 \%\right.$ (Figure 2$)$.

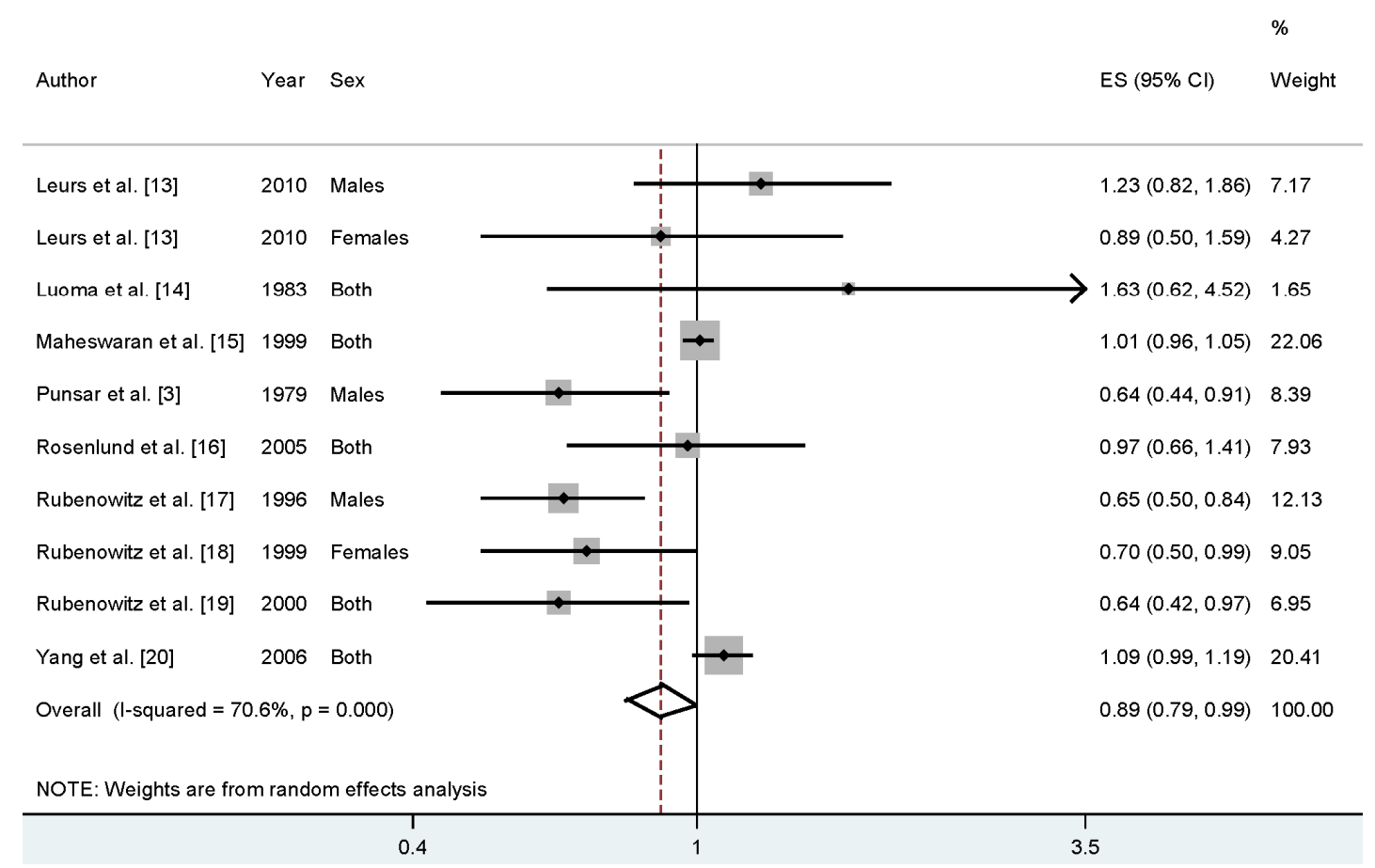

Figure 2. The forest plot between the levels of magnesium in drinking water and CHD mortality risk. 


\subsection{Meta-Regression and Subgroup Analysis}

In the pooled results, high heterogeneity $\left(I^{2}=70.6 \%, P_{\text {heterogeneity }}=0.000\right)$ was found. Thus, we conducted univariate meta-regression to explore the cause of this high heterogeneity with the covariates of publication year, location, sex, study type, CHD mortality outcome, and number of cases. No significant association was found in the above covariates.

There were seven studies conducted in case-control design and three conducted in cohort design, and the RR was 0.87 for case-control studies $(95 \% \mathrm{CI}=0.76-0.98)$. However, the association was nonsignificant in the cohort studies. In subgroup analyses for geographic locations, the highest levels of magnesium in drinking water versus the lowest levels were significantly associated with reduced risk of CHD mortality in Europe (summary $\mathrm{RR}=0.83,95 \% \mathrm{CI}=0.69-0.98$ ). There were three studies that reported the association in males and two studies in females. However, no significant associations were found either in males or females. Furthermore, in stratified analysis by CHD mortality outcomes, the association was only significant in the MI group $(R R=0.81$, $95 \% \mathrm{CI}=0.64-0.98$ ). Detailed results for the overall and subgroup analyses are shown in Table 2.

Table 2. Summary risk estimates of the levels of magnesium in drinking water and CHD mortality risk.

\begin{tabular}{|c|c|c|c|c|c|}
\hline \multirow{2}{*}{ Subgroups } & \multirow{2}{*}{$\begin{array}{c}\text { No. } \\
\text { Cases }\end{array}$} & \multirow{2}{*}{$\begin{array}{c}\text { No. } \\
\text { Studies }\end{array}$} & \multirow{2}{*}{ RR $(95 \%$ CI) } & \multicolumn{2}{|c|}{ Heterogeneity Test } \\
\hline & & & & $I^{2}(\%)$ & $p$-Value \\
\hline All studies & 77,821 & 10 & $0.89(0.79-0.99)$ & 70.6 & 0.000 \\
\hline \multicolumn{6}{|c|}{ Study design } \\
\hline Cohort & 1840 & 3 & $0.88(0.57-1.34)$ & 63.5 & 0.064 \\
\hline Case-control & 75,981 & 7 & $0.87(0.76-0.98)$ & 74.6 & 0.001 \\
\hline \multicolumn{6}{|c|}{ Geographic locations } \\
\hline Europe & 67,727 & 9 & $0.83(0.69-0.98)$ & 70.0 & 0.001 \\
\hline Asia & 10,094 & 1 & - & - & - \\
\hline \multicolumn{6}{|c|}{ CHD outcome } \\
\hline IHD & 65,868 & 3 & $1.01(0.96-1.05)$ & 0.0 & 0.586 \\
\hline MI & 11,755 & 6 & $0.81(0.64-0.98)$ & 78.6 & 0.000 \\
\hline $\mathrm{CHD}$ & 198 & 1 & - & - & - \\
\hline \multicolumn{6}{|c|}{ Sex } \\
\hline Males & 2194 & 3 & $0.78(0.54-1.15)$ & 73.3 & 0.024 \\
\hline Females & 878 & 2 & $0.75(0.56-1.00)$ & 0.0 & 0.484 \\
\hline
\end{tabular}

Abbreviations: CHD, coronary heart disease; IHD, ischemic heart disease; MI, myocardial infarction; $\mathrm{CI}$, confidence interval; RR, relative risk.

\subsection{Sensitivity Analysis and Small Study Effect}

Sensitivity analysis (Figure 3) did not identify any one individual study that strongly influenced the results on drinking water magnesium levels and CHD mortality risk publication bias between drinking water magnesium levels and CHD mortality was confirmed by Egger's test $(p=0.475)$.

\section{Discussion}

We conducted the first comprehensive meta-analysis that looked at an association between drinking water magnesium levels and CHD mortality risk. The findings from this meta-analysis suggest that the high levels of magnesium in drinking water may reduce the risk of CHD mortality. The association was also found in case-control studies, as well as in the European population.

In our pooled results, we found evidence of high between-study heterogeneity. A previous study [21] had reported that between-study heterogeneity is common in meta-analyses. Therefore, meta-regression with publication year, location, sex, study type, CHD mortality outcome, and number of cases was used to explore potential covariates which might cause this high between-study 
heterogeneity. Unfortunately, using the above mentioned covariates, no significant association was found to be the cause of the high heterogeneity. Furthermore, we conducted the subgroup analysis by geographic location, study design, CHD outcomes and sex to explore the potential heterogeneity, and heterogeneities did arise in some subgroup analyses.

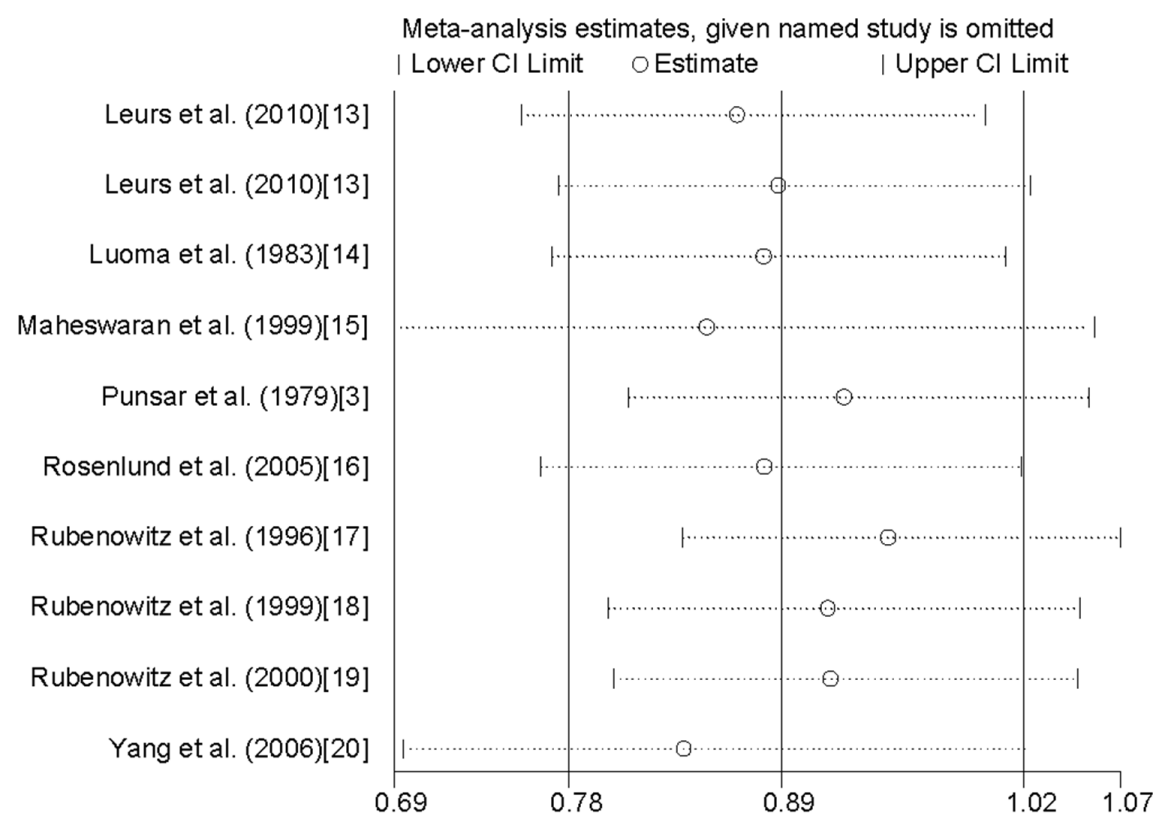

Figure 3. Analysis of influence of individual study on the association between the levels of magnesium in drinking water and CHD mortality risk.

A highlight of this study is the large sample size (77,821 cases) we were able to utilize in finding an inverse association between drinking water magnesium levels and CHD mortality risk. But, there are also some limitations in our study. First, nine of the 10 studies were conducted in Europe, and only one study was in China. A significant association was found only when we pooled the results for the subgroup of European studies. Notably, six of the ten studies came from Scandinavia (Sweden and Finland). Therefore, the results may be more applicable to the European population, and especially to Scandinavian populations. More studies originating in other countries are required to assess this association. Second, our study included seven retrospective studies and three cohort studies. For retrospective studies, original studies could cause some recall or selection bias, but proper epidemiological method requires clarification of the association in the original article. In our results, the association was only significant in retrospective studies, but not in cohort studies. This is because only three studies included in this study were cohort design. Therefore, further studies with cohort design are required. Third, there are only few studies which report the association between the level of magnesium in drinking water and CHD mortality for males and females respectively. Although we pooled the results for the subgroup analysis by sex, the small sample size of studies lead to lower statistical power. Finally, we found evidence of high between-study heterogeneity in the pooled analysis and some subgroup analyses. However, meta-regression could not explain this high heterogeneity. Thus, some other genetic and environment variables may affect this high heterogeneity.

In conclusion, findings from this study showed that a higher level of magnesium in drinking water was significantly inversely associated with the risk of CHD mortality, especially among Scandinavian populations.

Author Contributions: Conceived the study: L.J. and P.H.; Carried out the literature search: L.J., P.H. and J.C.; Data extraction: L.J., P.H. and J.C.; Analyzed the data: Y.L. and D.L.; Drafted the manuscript: L.J., G.Q. and N.T.

Conflicts of Interest: The authors declare no conflict of interest. 


\section{References}

1. Lozano, R.; Naghavi, M.; Foreman, K.; Lim, S.; Shibuya, K.; Aboyans, V.; Abraham, J.; Adair, T.; Aggarwal, R.; Ahn, S.Y.; et al. Global and regional mortality from 235 causes of death for 20 age groups in 1990 and 2010: A systematic analysis for the Global Burden of Disease Study 2010. Lancet 2012, 380, 2095-2128. [CrossRef]

2. Murray, C.J.; Lopez, A.D. Alternative projections of mortality and disability by cause 1990-2020: Global Burden of Disease Study. Lancet 1997, 349, 1498-1504. [CrossRef]

3. Punsar, S.; Karvonen, M.J. Drinking water quality and sudden death: Observations from West and East Finland. Cardiology 1979, 64, 24-34. [CrossRef] [PubMed]

4. Meyers, D. Mortality and water hardness. Lancet 1975, 1, 398-399. [CrossRef]

5. Galan, P.; Preziosi, P.; Durlach, V.; Valeix, P.; Ribas, L.; Bouzid, D.; Favier, A.; Hercberg, S. Dietary magnesium intake in a French adult population. Magnes. Res. 1997, 10, 321-328. [PubMed]

6. Turlapaty, P.D.; Altura, B.M. Magnesium deficiency produces spasms of coronary arteries: Relationship to etiology of sudden death ischemic heart disease. Science 1980, 208, 198-200. [CrossRef] [PubMed]

7. Chipperfield, B.; Chipperfield, J.R. Heart-muscle magnesium, potassium, and zinc concentrations after sudden death from heart-disease. Lancet 1973, 2, 293-296. [CrossRef]

8. DerSimonian, R.; Laird, N. Meta-analysis in clinical trials. Control. Clin. Trials 1986, 7, 177-188. [CrossRef]

9. Higgins, J.P.; Thompson, S.G.; Deeks, J.J.; Altman, D.G. Measuring inconsistency in meta-analyses. Br. Méd. J. 2003, 327, 557-560. [CrossRef] [PubMed]

10. Higgins, J.P.; Thompson, S.G. Controlling the risk of spurious findings from meta-regression. Stat. Méd. 2004, 23, 1663-1682. [CrossRef] [PubMed]

11. Egger, M.; Davey Smith, G.; Schneider, M.; Minder, C. Bias in meta-analysis detected by a simple, graphical test. Br. Méd. J. 1997, 315, 629-634. [CrossRef]

12. Tobias, A. Assessing the influence of a single study in the meta-analysis estimate. Stata Tech. Bull. 1999, 47, 15-17.

13. Leurs, L.J.; Schouten, L.J.; Mons, M.N.; Goldbohm, R.A.; van den Brandt, P.A. Relationship between tap water hardness, magnesium, and calcium concentration and mortality due to ischemic heart disease or stroke in The Netherlands. Environ. Health Perspect. 2010, 118, 414-420. [CrossRef] [PubMed]

14. Luoma, H.; Aromaa, A.; Helminen, S.; Murtomaa, H.; Kiviluoto, L.; Punsar, S.; Knekt, P. Risk of myocardial infarction in Finnish men in relation to fluoride, magnesium and calcium concentration in drinking water. Acta Méd. Scand. 1983, 213, 171-176. [CrossRef] [PubMed]

15. Maheswaran, R.; Morris, S.; Falconer, S.; Grossinho, A.; Perry, I.; Wakefield, J.; Elliott, P. Magnesium in drinking water supplies and mortality from acute myocardial infarction in north west England. Heart 1999, 82, 455-460. [CrossRef] [PubMed]

16. Rosenlund, M.; Berglind, N.; Hallqvist, J.; Bellander, T.; Bluhm, G. Daily intake of magnesium and calcium from drinking water in relation to myocardial infarction. Epidemiology 2005, 16, 570-576. [CrossRef] [PubMed]

17. Rubenowitz, E.; Axelsson, G.; Rylander, R. Magnesium in drinking water and death from acute myocardial infarction. Am. J. Epidemiol. 1996, 143, 456-462. [CrossRef] [PubMed]

18. Rubenowitz, E.; Axelsson, G.; Rylander, R. Magnesium and calcium in drinking water and death from acute myocardial infarction in women. Epidemiology 1999, 10, 31-36. [CrossRef] [PubMed]

19. Rubenowitz, E.; Molin, I.; Axelsson, G.; Rylander, R. Magnesium in drinking water in relation to morbidity and mortality from acute myocardial infarction. Epidemiology 2000, 11, 416-421. [CrossRef] [PubMed]

20. Yang, C.Y.; Chang, C.C.; Tsai, S.S.; Chiu, H.F. Calcium and magnesium in drinking water and risk of death from acute myocardial infarction in Taiwan. Environ. Res. 2006, 101, 407-411. [CrossRef] [PubMed]

21. Munafo, M.R.; Flint, J. Meta-analysis of genetic association studies. TRENDS Genet. 2004, 20, 439-444. [CrossRef] [PubMed]

(C) 2016 by the authors; licensee MDPI, Basel, Switzerland. This article is an open access article distributed under the terms and conditions of the Creative Commons by Attribution (CC-BY) license (http://creativecommons.org/licenses/by/4.0/). 